Nina Polovina ${ }^{1}$

Tanja Dinić ${ }^{2}$

Univerzitet u Beogradu

Saobraćajni fakultet
удК 316.77:659.1

DOI 10.18485/zivjez.2016.36.1.3

Оригинални научни рад

\title{
TIPOLOGIJA LIČNIH OGLASA KAO LINGVISTIČKIH I KULTUROLOŠKIH KATEGORIJA
}

Rad se bavi ličnim oglasima kao specifičnom vrstom teksta, pod pretpostavkom da je na osnovu velikog broja koncepata koji iz njih proizlaze moguće izvesti određene zaključke o dotičnoj kulturi i društvu. Uzimajući u obzir dva medija masovne komunikacije, štampu i internet, oglasi su precizno definisani u pogledu funkcije i strukture, kao i konteksta u kojem se realizuju. Potom se oblikuje predlog tipologije oglasa kao osnov za kulturološko tumačenje. Budući da analiza obuhvata srpske i nemačke oglase, kontrastivni pristup omogućio je i poređenje rezultata dobijenih za ove dve kulture, te utvrđivanje sličnosti i razlika među njima.

Ključne reči: društvo, jezik, komunikacija, kultura, lični oglas, medij, tipologija, vrednost, vrsta teksta

\section{Pojam ličnih oglasa}

Oglasi su objave različitog tipa koje mogu da se realizuju u mnogim vrstama medija: u štampi, na radiju, na televiziji i internetu. Tip medija u izvesnoj meri postavlja ograničenja u pogledu strukture ili obima oglasa, ali time ne ugrožava njegovo adekvatno identifikovanje. Za potrebe ovog rada u obzir će biti uzeta dva dominantna medija u oglašavanju: štampa i internet.

Dofifat i Vilke (1976: 179) oglase definišu kao vrstu objave koja na očigledan način služi isključivo ličnim interesima emitenta. Oglasi postoje otkad postoje i novine, najstariji masovni medij, jer su još prve novine iz rimskog doba, tzv. acta diurna ili acta publica,

1 n.polovina@sf.bg.ac.rs

2 t.dinic@sf.bg.ac.rs 
sadržavale različite vrste objava. Sistematska primena oglasa počinje tek u XVII veku. Oglasi se u današnje vreme obično klasifikuju kao službeni (npr. glasnici stranaka ili službi), privatni (objavljivanje vesti o rođenju, venčanju i smrti) ili mali oglasi (svi oglasi koji ne služe objavljivanju činjenica niti najavi službenih događanja, već su posvećeni ponudi ili potražnji jednog proizvoda, asortimana, usluge, partnera i sl.) (Dofifat i Vilke 1976: 183). Lični oglasi bi, stoga, bili podvrsta malih oglasa, privatni oglasi koji služe pronalaženju partnera za različite svrhe (brak, prijateljstvo, druženje, sport, putovanje i sl.) ili specifična vrsta porodičnih oglasa (Zomerfelt 2001: 24). Riman (1999: 38) ističe kako je cilj oglasa uspostavljanje kontakta sa jednom ili više nepoznatih osoba, pri čemu oglas mogu da daju privatna lica, ali i određene agencije ili institucije u njihovo ime. Osim toga, njihovo objavljivanje neminovno podrazumeva izvesno predznanje emitenta o formi, intenciji i načinu funkcionisanja ove vrste teksta.

\section{Karakteristike ličnih oglasa}

Prihvatajući pretpostavku predznanja u slučaju ličnih oglasa, Riman (1999: 62) navodi kako je emitent pre formulisanja svog ličnog oglasa došao u dodir s oglasima drugih oglašivača, pa je njegova uloga u suštini obrnuta, jer je on prvobitno bio recipijent (nekog ranijeg oglasa), a tek potom postao producent. Navedena zamena uloga u komunikativnom procesu nastajanja ličnog oglasa samo je prva od nekoliko specifičnosti koje odlikuju ovu tekstualnu vrstu.

Lični oglasi se najčešće objavljuju u novinama ili na internetu, dakle u masovnim medijima, koji su po svojoj suštini usmereni na različitu i veoma brojnu publiku. Međutim, druga važna karakteristika ličnih oglasa je upravo u tome što producenti koriste masovni medij iako svoje oglase nisu namenili toliko širokom auditorijumu, već žele da ograniče tip i broj recipijenata. To postižu sadržajnim elementima, odnosno mehanizmima selekcije ili odvraćanja od reakcija na oglas - verbalizacijom poželjnih ili nepoželjnih kategorija.

Dakle, cilj ličnih oglasa jeste kontakt s potpuno nepoznatom, ali odabranom osobom, putem medija koji je dostupan gotovo svima. Kako bi se u toj nameri uspelo, dolazi do znatnog kršenja društve- 
nih normi. Naime, kod uobičajenog uspostavljanja kontakta, prve susrete odlikuje određena rezervisanost i obazrivost u otkrivanju detalja, dok je kod ličnih oglasa prvi korak obeležen iznošenjem velikog broja detalja o sebi ili potencijalnom partneru. Upravo takvo nepoštovanje normi Marfurt ističe kao značajnu karakteristiku ličnih oglasa jer do takvog razvoja događaja u klasičnom upoznavanju dolazi tek postepeno, nakon određenog vremenskog perioda (Hofart 2009: 41). S druge strane, kako bi do kontakta uopšte došlo, emitent je prinuđen da odabere određene, relevantne informacije koje zalaze u domen privatnog i da ih objavi u javnom glasilu.

Osim navedenih obeležja ličnih oglasa, značajno je pomenuti i mogućnost njihovog istraživanja radi izvođenja zaključaka o nekom društvu. Činjenica je da ovi oglasi na prvi pogled sadrže samo informacije o samom oglašivaču i njegove potpuno individualne želje u pogledu potencijalnog partnera i njihovog budućeg odnosa. Čak se postavlja i pitanje do koje mere su navodi koje oglašivač objavljuje iskreni i tačni jer specifičnost ovog vida kontakta omogućava preoblikovanje ili zaobilaženje istine. Međutim, bez obzira na to da li su navodi emitenta istiniti, delimično istiniti ili lažni, oni upućuju na to koje osobine, tipove odnosa ili ponašanja emitent kao pripadnik jednog društva smatra poželjnim ili značajnim ,jer se svakodnevica pre svega odnosi na sferu privatnosti, ali je uprkos svemu pod uticajem vrednosnih kanona utemeljenih u društvu“3 (Hajneman 2000: 605). Dakle, kroz prikaz sebe i partnera, bez obzira na to $\mathrm{u}$ kojoj meri on odgovara realnosti ili istini, emitent stvara sliku o idealnom (ili prihvatljivom) pojedincu u određenoj društvenoj zajednici, o vrednostima i ponašanju koji se u njoj traže.

\section{Lični oglasi u kontekstu kulture}

Kulturu čine brojni segmenti svakodnevnog života; ona je okvir i suština svakog delanja pojedinca. S obzirom na to da se radi o tako složenoj i duboko prisutnoj pojavi, nije je moguće proučavati direk-

3 " [...] da sich Alltag vorrangig im privaten Bereich vollzieht, der aber trotz allem von einem gesamtgesellschaftlichen Wertekanon bestimmt wird“ (Hajneman 2000: 605). 
tno jer ne postoje parametri na osnovu kojih bi se o njoj izvodili relevantni zaključci, već je neophodno istraživanje obaviti posredno, kroz manifestacije kulture u nekom materijalnom obliku, npr. putem kategorija realizovanih u ličnim oglasima ${ }^{4}$ (Riman 1999: 77; Kremer 1998: 24). Lični oglasi se, pritom, koriste dvojako: s jedne strane - isključivo da bi emitenti ostvarili svoj lični cilj i pronašli partnera, s druge strane - kako bi istraživači dobili nereaktivne podatke o situaciji u društvu. Posmatrajući kulturu kroz prizmu ličnih oglasa, istraživanje je uzelo u obzir dva kulturna okruženja - srpsko i nemačko - kako bi se kontrastiranjem elemenata istakle sličnosti i razlike među njima.

U oba društva lični oglasi su stabilna tekstualna vrsta, iako se njihova procentualna zastupljenost razlikuje. ${ }^{5}$ Postavlja se pitanje zašto se emitenti umesto direktnog i neposrednog kontakta uopšte odlučuju za ovakvo upoznavanje sa ljudima kad se ima u vidu do koje mere je ovakav način komunikacije specifičan. Odgovor nam pružaju konkretne prilike u modernom društvu, koje se kreću u pravcu industrijalizacije, napuštanja sela i prelaska u gradove, sve većeg slabljenja porodičnih odnosa, češćeg razvoda brakova, postepenog prihvatanja alternativnih odnosa, jačanja individualizacije i otuđenja pojedinca. One stvaraju atmosferu u kojoj je sve teže pronaći adekvatnog partnera jer su kriterijumi podignuti, orijentacija društva izmenjena ka potrošačkom, a vrednosti i moral postavljeni na inovirane ili modifikovane osnove koje nije lako dostići. I dok pritisak ka individualizaciji s jedne strane otežava uspostavljanje partnerskih odnosa, s druge strane, kako navodi Bek (1986: 187), upravo individualizacija koja razdvaja muškarca i ženu istovremeno podstiče njihovo ponovno spajanje jer rastakanje tradicije vodi ka sve većim očekivanjima od samog partnerstva. Postojanje ličnih

4 Pritom, treba imati u vidu da istraživanje ovakvog tipa ima svoja ograničenja jer se postavlja pitanje koliko su oglašivači reprezentativan uzorak populacije. S druge strane, takav uzorak neminovno obuhvata ljude različitog uzrasta, različitog porekla, interesovanja, statusa i afiniteta, pa je na osnovu takvog istraživanja moguće doneti određene zaključke o samom društvu.

5 Broj objavljenih oglasa u Srbiji (procentualno izražen u odnosu na broj stanovnika) manji je gotovo dva puta od broja oglasa u Nemačkoj. Razlozi su višestruki - od navika čitalaca, preko tiraža novina, finansijske situacije do razlika u mentalitetu. 
oglasa je, stoga, jedna od nužnih karika u ponovnom uspostavljanju ravnoteže u međuljudskim odnosima.

\section{Lični oglasi kao vrsta teksta}

Pojam ličnih oglasa danas obuhvata čitav dijapazon specifično oblikovanih tekstova u vidu privatnih reklamnih panoa koji se pojavljuju u različitim medijima. Polaznu osnovu prilikom definisanja ličnih oglasa kao vrste teksta pružiće Brinkerov trostepeni model (Brinker 1997: 133-141):

\subsection{Funkcionalni kriterijum}

Lični oglasi ubrajaju se u neknjiževne vrste (Gebrauchstexte), koje su po svom ustrojstvu usmerene na rešavanje određenog problema; smatra se da su u principu monofunkcionalne, odnosno da imaju jednu (dominantnu) komunikativnu funkciju (Rolf 2000: 423). Problem koji lični oglasi pokušavaju da reše je pronalaženje partnera, a to se obavlja pokretanjem niza komunikativnih aktivnosti koje treba da podstaknu recipijenta na reakciju i interakciju, pri čemu sam podsticaj ne mora da bude eksplicitno verbalizovan (javi se, pozovi i sl.), već je direktivnost i apelativnost ove tekstualne vrste implicitno sadržana u njenom složenom kontekstualno-situativnom okruženju. Svakako se ne može tvrditi da postoji samo jedna funkcija ličnih oglasa, već autori govore o najmanje dve funkcije (ili više njih), pri čemu su one hijerarhijski ustrojene po principu uklapanja ilokucija. Pritom, ne postoji saglasnost čak ni oko toga koja je funkcija u ovoj tekstualnoj vrsti dominantna.

Neki autori (Rutkovski 2003, Rolf 2000) ističu da lični oglasi pripadaju tekstovima sa dominantnom kontaktnom funkcijom jer emitent „daje do znanja adresatu da mu je stalo do uspostavljanja ličnog odnosa"6 (Brinker 2000: 176), a to potkrepljuju i argumentima koji se odnose na ciljni odabir rubrike ili naslova pod kojima se

6 „[...] dem Adressaten zu verstehen, dass es ihm um die personale Beziehung zum Adressaten geht" (Brinker 2000: 176). 
oglasi objavljuju (On traži nju, Poznanstva i sl.) ili samim nazivom ličnog oglasa, koji ukazuje da se prvenstveno radi o želji za podsticanjem kontakta (kontaktni oglas ili Kontaktanzeige). Budući da se kod ove vrste teksta kontaktna funkcija ogleda u želji za uspostavljanjem kontakta, lični oglasi nisu idealan primer jer se kontaktna funkcija najčešće odnosi na situacije u kojima su komunikatori već ranije bili u kontaktu, pa su jedan drugome poznati, što ovde nije slučaj (Hofart 2009: 45). S druge strane, kontakt zaista jeste primarni cilj emitenta, a do tog cilja se može stići ispunjavanjem još jedne funkcije - apelativne (prema Brinkerovoj terminologiji) ili direktivne (prema Serlovoj terminologiji).

Apelativna funkcija, u ovom kontekstu, veoma je slična kontaktnoj, ali je specifičnost apelativnih tekstova usmerenost na to da se adresat podstakne na konkretno delanje. „Emitent daje adresatu do znanja da želi da ga podstakne [...] da obavi određeno delanje (uticaj na ponašanje)“" (Brinker 2000: 176). ${ }^{7}$ Željena reakcija svakako se odvija u vidu uspostavljanja kontakta, pa eksplicitno isticanje apelativne ili kontaktne funkcije deluje kao preklapanje, jer apelativna funkcija u ovom slučaju podrazumeva kontaktnu kao svoj suštinski deo.

Ukoliko prihvatimo da je dominantna funkcija ličnih oglasa apelativna, onda bi ova vrsta teksta mogla da ima još nekoliko dodatnih funkcija koje na odlučujući način utiču na uspešnost komunikativnog akta i na formiranje same tekstualne vrste, a koje se direktno ili indirektno manifestuju kroz jezik. Ukoliko je ne shvatimo kao imanentni deo reakcije na apel, kontaktna funkcija bi svakako bila najznačajnija funkcija koja konstituiše ovu vrstu teksta.

Značajna sekundarna funkcija jeste i informativna funkcija. Ona se ogleda u stvaranju svojevrsne baze podataka o osobi koja oglas objavljuje i/ili o osobi koja bi trebalo na oglas da odgovori, čime nastaje podloga za komunikativnu reakciju. Informativna funkcija je samo podrška apelativnoj, ali Štolt (1976: 27) navodi da iz samih činjenica u komunikativnom procesu nastaju argumenti sa persuazivnom funkcijom: na osnovu konkretnog teksta u komuni-

7 „Der Emittent gibt dem Adressaten zu verstehen, dass er ihn dazu bewegen will, [...] eine bestimmte Handlung zu vollziehen (Verhaltensbeeinflussung)." (Brinker 2000: 176). 
kativnom aktu, polazeći od prvog smisla ili namere (putem jezičkog iskaza), adresat treba da konstituiše drugi smisao ili nameru (pravo značenje teksta) kroz proces komunikacije.

Uzimajući u obzir činjenicu da se lični oglasi plasiraju u masovnom mediju, da su izloženi javnosti i veoma brojnoj publici, emitent neminovno u svoj oglas utiskuje još jednu sekundarnu, ali ne manje važnu funkciju, a to je selektivna (Rutkovski 2003: 12) ili repelativna (Štolt 1976: 29) funkcija. Naime, tekst oglasa nije namenjen baš svima, već emitent, iznoseći pažljivo odabrane informacije o sebi i potencijalnom partneru, želi da pokuša da unapred utiče na to ko će reagovati na njegov oglas. Stoga, lični oglasi nisu prosto samoreklame - upravo ih postupak selekcije neadekvatnih partnera izdvaja od ove vrste teksta. Kako bi adekvatno realizovali selektivno-repelativnu funkciju, lični oglasi treba da budu pažljivo sastavljeni u jezičkom smislu, ali i da nedvosmisleno deluju u komunikativnom aktu, što je prilično složen zadatak budući da podrazumeva visok stepen predviđanja kako u domenu psihologije, tako i u domenu sociologije, kulturologije i drugih oblasti svakodnevnog života.

Treba pomenuti i gotovo neprimetnu, ali za komunikativnu situaciju (i iz ugla emitenta i iz ugla adresata) značajnu - obligatornu funkciju ličnih oglasa. Ova funkcija komunikatore obavezuje na ozbiljnost u namerama i potragu zasnovanu na stvarnoj želji i potrebi.

\subsection{Kontekstualni kriterijum}

Budući da je svaki realizovan tekst deo neke situacije, nekog komunikativnog okvira, sledeća kategorija na osnovu koje Brinker vrši diferencijaciju vrsta tekstova jeste kontekst. Osim indikatora funkcije teksta, na ukupnu ilokuciju utiču i kontekstualni indikatori (Brinker 2000: 180) kao što su npr. rubrika u kojoj se oglas objavljuje, medijsko okruženje, situativno okruženje, forma komunikacije, pripadnost određenoj vrsti teksta i sl. Kontekst istraženih ličnih oglasa je pre svega određen sredstvom komunikacije: novine (štampani medij) ili internet (elektronski medij). Lični oglasi se u izvesnoj meri izdvajaju iz vizuelnog okruženja medija i iz drugih priloga po tipografskim karakteristikama, boji, grafičkom odvajanju putem okvira, postojanju fotografije ili po nekim drugim vi- 
zuelnim mogućnostima. Iako je teoretski moguća i usmena forma (na televiziji ili radiju), lični oglasi su u najvećem broju slučajeva pisani tekstovi. Zanimljivo je istaći i smer komunikacije, koji je faktički monolog, jer emitent iznosi informacije u etar, a direktna i neposredna reakcija adresata izostaje, pa govorimo o jednosmernoj komunikaciji. Ipak, uspostavljanje komunikativnog kontakta je moguće postići samo kroz dijalošku formu. Specifičnost ličnih oglasa je upravo to što dijalog poprima oblik monologa (Marfurt 1978: 27) jer emitent formira tekst anticipirajući približnu reakciju adresata i zamišljajući poželjan komunikativni odgovor, tako da se interakcija u stvari unapred simulira. Između komunikatora nema direktnog akustičkog ili neposrednog kontakta, već je mogućnost reakcije i interakcije odložena i u vremenu i u prostoru, pa je komunikativni odgovor osmišljen i ciljan, usmeren na postizanje maksimalnog efekta. Štolt (1976) na sličan način komunikaciju kod ličnih oglasa određuje kao monološku, pisanu i nespontanu.

Komunikacioni akt neminovno se realizuje u okviru određene oblasti delovanja. Lične oglase odlikuje već pomenuta dihotomija. S obzirom na to da se radi o tekstu koji formira pojedinac, unoseći u njega lične i individualne podatke i dajući mu lični pečat, oblast delovanja je svakako privatna, odnosno neformalna jer emitent i adresat u komunikaciji uvek nastupaju kao pojedinačni aktanti. ${ }^{8}$ $\mathrm{S}$ druge strane, publikovanje oglasa u masovnom mediju utiče na njegovo realizovanje kroz oblast javnog jer emitent nastupa pred nepoznatom publikom. Izvestan osećaj zaštićenosti pruža anonimnost komunikatora jer se u ličnim oglasima uglavnom ne navodi ime i prezime, nego šifra oglasa, elektronska adresa ili, eventualno, broj telefona. Ovaj neobični spoj privatnog i javnog za lične oglase je od suštinske važnosti.

\subsection{Strukturni kriterijum}

Strukturni kriterijum se odnosi na samu temu i način njenog prikazivanja, te na karakterističnu upotrebu jezičkih sredstava. Lični oglasi imaju tačno definisanu temu (uspostavljanje kontakta radi

$8 \quad$ Čak i kad neka agencija ili institucija daje oglas umesto pojedinca, ona nastupa u njegovo ime, pa se i tada može govoriti o pojedinačnom kontaktu. 
neke vrste partnerskog odnosa) od koje se gotovo nikad ne odstupa jer bi to bilo uzaludno trošenje vremena, kao i potencijalni finansijski gubitak. Upravo ta sadržajna i tematska konstantnost, ali i stabilna forma (Hofart 2009: 44) izdvajaju lične oglase od drugih vrsta oglasa koji se objavljuju u masovnim medijima. Način razvoja teme ličnih oglasa je pretežno deskriptivan - opis emitenta i partnera i njihove potencijalne veze. Osim toga, nailazimo i na argumentativni način razvoja teme jer je, osim davanja opisa, neophodno ubediti recipijenta i da je upravo određena osoba za njega adekvatna i da upravo na taj oglas treba da odgovori. Tematska struktura oglasa ogleda se kroz manji broj podređenih tema kao što su prikaz emitenta, prikaz poželjnog partnera i tipa odnosa. Kroz te teme se, iznošenjem pojedinosti (starost, izgled, karakteristike, vrsta veze i sl.), vrši persuazivno dejstvo. Osim tematskih elemenata, na strukturu ličnih oglasa kao vrste teksta utiču i upotrebljena jezička sredstva. Karakteristična su različita leksička i sintaksičko-semantička sredstva kao što su: veliki broj imenica i prideva, a mali broj glagola, nabrajanje elemenata prilikom opisa, eliptične konstrukcije i upotreba skraćenica, različite floskule, upitne ili uzvične rečenice kao podsticaj na delanje i sl. Jezička sredstva su usklađena s ustaljenom formom ličnih oglasa i relativnom normiranošću sadržaja koji se u njima pojavljuje. Čak i kad su potpuno inventivni, lični oglasi se lako identifikuju kao određena vrsta teksta - prema predznanju komunikatora, ali i prema poziciji u mediju u kojem su objavljeni (rubrika, poseban odeljak i sl.). ${ }^{9}$

Tekstualna struktura ličnih oglasa je relativno stabilna, bez značajnih odstupanja, a Kapland (1996: 193 cit. prema Ganzel 2011: 118) navodi da se svaki lični oglas može svesti na konvencionalnu strukturu, odnosno prototipsku formu:

9 Istraživanje stepena prepoznatljivosti različitih vrsta teksta, odnosno sposobnosti njihove ispravne klasifikacije obavio je Dimter (1981: 123126), izostavljajući suštinske elemente ili ih zamenjujući elementima slične strukture, ali bez uklapanja značenja. Proučavao je do koje mere recipijenti ispravno prepoznaju vrstu teksta u situaciji kad nedostaje deo konteksta ili sadržaja. Rezultati su pokazali da je stepen prepoznatljivosti ličnih oglasa oko 78\%. To je gotovo najviši stepen ako se uzmu u obzir sve vrste tekstova, pogotovo kad se ima u vidu da ovaj tip teksta nema nikakav standardizovan uvod, već je tekst zbog ekonomičnosti, izbegavanja redundantnog ili održavanja pažnje sveden na izražavanje suštinskih sadržaja. 
1. emitent,

2. traži,

3. adresat,

4. cilj ili namera,

5. komentar,

6. reference,

pri čemu su pozicije od 1 do 4 obligatorne, dok su pozicije 5 i 6 fakultativne. Čak i najinventivniji i potpuno alternativni oglasi moraju da imaju formu: X (1 - emitent) traži (2) Y (3 - adresat) radi Z (4 - cilj). Na sličan način strukturu određuje i Štolt (1976: 28), navodeći minimum elemenata bez kojeg lični oglas ne bi mogao da postoji: ko (S - Selbstbezeichnung, definisanje emitenta) traži koga (P - Partner(in)bezeichnung, definisanje adresata) radi čega $(\mathrm{H}-$ Heiratsabsicht, namera ili cilj). ${ }^{10}$ Lični oglasi, iako često imaju svedenu formu, poseduju solidan stepen informativnosti: na malom prostoru se nalazi veliki broj podataka - što eksplicitno iskazanih, što implicitno sadržanih u oglasu.

Lični oglasi su relativno kratki i jezički često nepotpuni ili nedorečeni, ali su veoma koncentrovanog sadržaja, pa čine značajan korpus na osnovu kojeg neposredno mogu da se izvedu zaključci o producentu i recipijentu, načinu stvaranja njihovog identiteta i međusobnog odnosa, a posredno i o samom društvu, vrednostima, normama, klišeima i stereotipima koji njime vladaju.

\section{Tipologija ličnih oglasa}

Posmatrajući lične oglase kao specifičnu vrstu teksta, rasprostranjenu u brojnim segmentima svakodnevice, možemo primetiti da se gotovo svaki oglas po nečemu izdvaja, da se ističe njegova posebnost, a da pritom recipijenti ipak nemaju nikakav problem da ga prepoznaju kao određenu vrstu teksta. U zbiru tolikih različitosti, neminovno je da postoje izvesna poklapanja i sličnosti jer bi ina-

10 U zavisnosti od konkretnog jezika na kojem je napisan lični oglas, obligatorni elementi mogu u specifičnim slučajevima dodatno da se redukuju na 'emitent traži adresata' ili na 'emitent traži radi', ali je to apsolutni minimum ispod kojeg se tekst oglasa ne može redukovati. 
če opstanak same vrste teksta bio ugrožen. Stoga se čini logičnim i opravdanim upustiti se u postupak tipologizacije ličnih oglasa s ciljem njihove sistematizacije.

U svetu su lični oglasi već godinama predmet brojnih naučnih proučavanja s različitim polaznim osnovama i iz različitih uglova, ali veoma retko se autori u okviru svojih istraživanja bave njihovom tipologijom. Stoga, pokušaj ove vrste nema istraživačku pozadinu u brojnoj literaturi, već predstavlja poduhvat za koji autori smatraju da je koristan i smislen. Budući da se nalaze u različitim medijima i da je njihov broj na dnevnom nivou prilično velik, nije moguće jednim istraživanjem obuhvatiti sve lične oglase koji se pojave u nekom društvu, kulturi ili zajednici. Ova tipologija zasnovana je na odabranom korpusu koji čine lični oglasi objavljeni jednog vikenda 2001. i jednog vikenda 2015. godine u srpskim i nemačkim nacionalnim ili nadregionalnim dnevnim novinama („Politika“, „Večernje novosti“, „Frankfurter Allgemeine Zeitung“, „Süddeutsche Zeitung“), regionalnim dnevnim novinama („Dnevnik“, „Kölner Stadt-Anzeiger“, „Sächsische Zeitung“), oglasnim novinama ${ }^{11}$ („Halo oglasi“) i na internet portalima (www.serbiancafe.com, www.markt.de). Takav odabir rezultirao je ukupnim brojem od 1906 ličnih oglasa na kojima je obavljeno istraživanje kroz poredeđenje dve kulture, dva vremenska perioda, ali i dve perspektive (muške i ženske).

Polazeći od poimanja ličnih oglasa u smislu tekstualne lingvistike, te uzimajući u obzir njihov kontekst, funkciju i strukturu, a sagledavajući i konkretnu, praktičnu, formalnu i sadržajnu komponentu oglasa, tipologija se zasniva na 4 kriterijuma, pri čemu se svaki od njih dalje deli na nekoliko segmenata:

1. lični oglasi prema polu oglašivača:

a) oglasi koje su formirali muškarci,

b) oglasi koje su formirale žene;

11 U nemačkom korpusu zastupljene su dve regionalne dnevne novine, a u srpskom korpusu samo jedne, jer veći broj regionalnih novina koje redovno izlaze (i objavljuju lične oglase) i ne postoji - umesto toga su u srpski korpus uvrštene jedne oglasne novine, jer su navike čitalaca u Srbiji takve da radije objavljuju u oglasniku nego u dnevnim novinama (o čemu svedoči broj publikovanih oglasa). 
2. lični oglasi prema tipu odnosa:

a) oglasi koji se objavljuju radi sklapanja braka,

b) oglasi koji se objavljuju radi partnerstva ili neke vrste poznanstva (sklapanje životne zajednice otvorenijeg tipa, veza bez eksplicitno izražene želje za brakom, bez obzira na to da li je homoseksualne ili heteroseksualne orijentacije),

c) oglasi koji se objavljuju s drugačijim namerama (prijateljstvo, zajedničko provođenje slobodnog vremena u vidu putovanja, sporta ili neke druge aktivnosti);

3. lični oglasi prema broju informacionih jedinica:

a) oglasi do 15 informacionih jedinica - kraći oglasi,

b) oglasi preko 15 informacionih jedinica - duži oglasi;

4. lični oglasi prema dominantnom sadržajnom usmerenju:

a) oglasi prvenstveno orijentisani na opis sebe, b oglasi prvenstveno orijentisani na opis partnera,

c) oglasi prvenstveno orijentisani na opis veze.

\subsection{Lični oglasi prema polu oglašivača}

Razvrstavanje ličnih oglasa prema polu oglašivača je kriterijum koji uzima u obzir praktične elemente oglasa u medijima, a usmeren je na ispitivanje stepena prihvatanja i upotrebe ove vrste teksta od strane muškaraca i žena kao oglašivača.

\begin{tabular}{|c|c|c|c|}
\hline Medij & $\begin{array}{c}\text { Muškarci traže } \\
\text { partnera/partnerku }\end{array}$ & $\begin{array}{c}\text { Žene traže } \\
\text { partnera/partnerku }\end{array}$ & $\begin{array}{c}\text { Nedefinisani } \\
\text { oglasi }\end{array}$ \\
\hline $\begin{array}{c}\text { Srpski } \\
\text { mediji }\end{array}$ & 24 oglasa ili $80 \%$ & 5 oglasa ili 16,7\% & 1 oglas ili 3,3\% \\
\hline $\begin{array}{c}\text { Nemački } \\
\text { mediji }\end{array}$ & 452 oglasa ili 47,3\% & 487 oglasa ili 50,9\% & $\begin{array}{c}16 \text { oglasa ili } \\
1,6 \%\end{array}$ \\
\hline
\end{tabular}

Tabela 1. Lični oglasi objavljeni 2001. godine 
TIPOLOGIJA LIČNIH OGLASA KAO LINGVISTIČKIH...

\begin{tabular}{|c|c|c|c|}
\hline Medij & $\begin{array}{c}\text { Muškarci traže } \\
\text { partnera/ partnerku }\end{array}$ & $\begin{array}{c}\text { Žene traže } \\
\text { partnera/ partnerku }\end{array}$ & $\begin{array}{c}\text { Nedefinisani } \\
\text { oglasi }\end{array}$ \\
\hline $\begin{array}{c}\text { Srpski } \\
\text { mediji }\end{array}$ & 73 oglasa ili 82,9\% & 15 oglasa ili 17,0\% & - \\
\hline $\begin{array}{c}\text { Nemački } \\
\text { mediji }\end{array}$ & 486 oglasa ili 58,3\% & 340 oglasa ili 40,8\% & $\begin{array}{c}7 \text { oglasa ili } \\
0.8 \%\end{array}$ \\
\hline
\end{tabular}

Tabela 2. Lični oglasi objavljeni 2015. godine

U srpskim oglasima oglašivači su u većini slučajeva muškarci (čak $80 \%$ oglasa), što je odraz situacije u srpskom društvu gde dominira patrijarhalizam, tj. gde je uloga muškarca da traži sebi par, dok se uloga žene svodi na pasivno čekanje da bude pronađena. Jasno izražena hijerarhija muško-ženskih odnosa ukazuje i na stepen modernizacije društva i nivo polne ravnopravnosti, koji uprkos prolaznosti vremena ne pokazuje čak ni naznake uravnoteženja. S druge strane, veća zastupljenost oglasa muškaraca u odnosu na oglase žena može da se tumači i kroz različito prihvatanje ove forme komunikacije usled očekivanja društva u smislu prihvatljivog ponašanja, prikazivanja i delanja.

Nemački oglasi pokazuju variranje rezultata u dijahronom sledu, i to suprotno prvobitnim očekivanjima od jednog postmodernistički uređenog društva. Pažljivije proučavanje statističkih podataka ipak nam ukazuje da razliku u zastupljenosti tzv. muških i ženskih oglasa čine oglasi objavljeni u elektronskim medijima, jer su rezultati iz 2015. godine bez oglasa s interneta gotovo isti kao rezultati iz 2001. godine. Skeptičnost žena ili njihovo slabije prihvatanje forme ličnih oglasa na internetu može se objasniti brojnim opasnostima kojima žene, kao stereotipno slabiji pol, mogu da budu izložene otkrivanjem svojih želja, potreba ili svoje intime. S druge strane, gotovo ravnopravno učešće muškaraca i žena (oko $50 \%$ ) u objavljivanju oglasa u skladu je s tendencijama prisutnim u modernom nemačkom društvu - ovde se misli na jednakost među polovima. 


\subsection{Lični oglasi prema tipu odnosa}

Proučavanje tipa odnosa koji oglašivači navode kao poželjan u svojim oglasima u direktnoj je vezi i sa samim nazivima rubrika u kojima se oglasi objavljuju. Kroz ovaj kriterijum, donekle, može da se vidi otvorenost ka alternativnim mogućnostima odnosa koja direktno ukazuje na stepen modernizacije. Ovde je prvenstveno naglasak na razlikovanju oglasa koji eksplicitno navode brak kao ciljni tip veze ili potenciraju druge oblike partnerstva (neobavezne ili trajne veze, povremena viđanja i sl.), te oglasa posvećenih pronalaženju partnera za sport, zajednička putovanja, slobodno vreme, druženje parova i druge oblike aktivnosti.

\begin{tabular}{|c|c|c|c|}
\hline Medij & $\begin{array}{c}\text { Tip odnosa: } \\
\text { brak }\end{array}$ & $\begin{array}{c}\text { Tip odnosa: } \\
\text { partnerstvo }\end{array}$ & $\begin{array}{c}\text { Ostali tipovi } \\
\text { odnosa }\end{array}$ \\
\hline Srpski mediji & $\begin{array}{c}19 \text { oglasa ili } \\
63,3 \%\end{array}$ & $\begin{array}{c}11 \text { oglasa ili } \\
36,7 \%\end{array}$ & - \\
\hline Nemački mediji & 24 oglasa ili $2,5 \%$ & $\begin{array}{c}797 \text { oglasa ili } \\
83,4 \%\end{array}$ & $\begin{array}{c}134 \text { oglasa ili } \\
14 \%\end{array}$ \\
\hline
\end{tabular}

Tabela 3. Lični oglasi objavljeni 2001. godine

\begin{tabular}{|c|c|c|c|}
\hline Medij & $\begin{array}{c}\text { Tip odnosa: } \\
\text { brak }\end{array}$ & $\begin{array}{c}\text { Tip odnosa: part- } \\
\text { nerstvo }\end{array}$ & $\begin{array}{c}\text { Ostali tipovi } \\
\text { odnosa }\end{array}$ \\
\hline Srpski mediji & $\begin{array}{c}25 \text { oglasa ili } \\
28,4 \%\end{array}$ & 51 oglasa ili $57,9 \%$ & $\begin{array}{c}12 \text { oglasa ili } \\
13,6 \%\end{array}$ \\
\hline Nemački mediji & $\begin{array}{c}24 \text { oglasa ili } \\
2,9 \%\end{array}$ & $\begin{array}{c}731 \text { oglasa ili } \\
87,7 \%\end{array}$ & $\begin{array}{c}78 \text { oglasa ili } \\
9,3 \%\end{array}$ \\
\hline
\end{tabular}

Tabela 4. Lični oglasi objavljeni 2015. godine

Statistička analiza pokazuje da je brak u srpskim ličnim oglasima 2001. godine bio dominantan i veoma poželjan tip veze sa zastupljenošću od 63,3\%. To potvrđuje osnovnu orijentaciju srpskog društva ka porodičnim vrednostima, koja potiče iz narodne tradicije, ali i iz shvatanja pravoslavne religije - brak se smatra primarnim načinom građenja partnerskog odnosa i krajnjim ciljem velikog 
broja sklopljenih kontakata. Navođenje braka kao poželjnog oblika veze u ličnim oglasima 2015. godine javlja se ređe nego u prethodnom periodu, ali je zastupljenost od $28,4 \%$ još uvek na nivou srednjih vrednosti i svakako je oblik zajednice koji ne treba zanemariti. Drugi, definisani ili nedefinisani oblici partnerskih odnosa doživeli su relativno velik porast u odnosu na period pre 14 godina. To se može shvatiti kao logičan odgovor društva na opadanje popularnosti braka i stvaranje većeg broja neformalnih zajednica usled uticaja modernih demografskih kretanja. Zanimljivo je posmatrati kategoriju ostalih tipova odnosa koja obuhvata ponude i potražnje ljudi za društvom u slobodnim aktivnostima, u sportu, na putovanjima i sl. Dok 2001. ne može da se pronađe nijedan oglas tog tipa, 2015. godine je, pod uticajem zapadnjačkog modela života koji postaje uzor, a koji je u velikoj meri okrenut industriji slobodnog vremena, statistička zastupljenost ovog tipa oglasa dostigla 13,6\%, što se poklapa s vrednostima dobijenim u modernim društvima.

Rezultati istraživanja nemačkog korpusa govore nam o ranom dostizanju (post)modernističko-individualističkog ideala: statistika iz 2001. godine se gotovo uopšte ne razlikuje od one iz 2015. godine. Dakle, tendencija napuštanja braka kao idealne i najzastupljenije vrste zajednice očigledna je u Nemačkoj još početkom 21. veka, dok je u Srbiji to proces koji uveliko traje. Veoma niska zastupljenost oglasa usmerenih ka braku (2,5-2,9\%) u skladu je s vrednosnom orijentacijom tog društva ka individualizmu. Okrenutost pojedinca sebi i sopstvenim potrebama, zadovoljavanje ličnih želja, bez brojnih porodičnih obaveza, preovlađujući je model ponašanja i razmišljanja. Izuzetno mali broj oglasa s iskazanom željom za brakom nadomešta velik broj oglasa s drugim, potpuno raznovrsnim tipovima partnerskih odnosa. Zanimljivo je istaći i da se partnerstva s pripadnicima istog pola traže potpuno otvoreno, kroz posebne rubrike u znatnom broju medija - što je u srpskim medijima izuzetno retko (u štampanim medijima u Srbiji, čak i u današnje vreme, to je potpuno nezamislivo, dok u elektronskim medijima postoji manji broj takvih primera). 
5.3. Lični oglasi prema broju informacionih jedinica

Dužina teksta oglasa je kategorija koja razlikuje kraće oglase (do 15 informacionih jedinica) i duže oglase (više od 15 informacionih jedinica). ${ }^{12}$

\begin{tabular}{|c|c|c|c|}
\hline Medij & Kraći oglasi & Duži oglasi & $\begin{array}{c}\text { Prosečna dužina } \\
\text { oglasa prema } \\
\text { broju informa- } \\
\text { cionih jedinica }\end{array}$ \\
\hline Srpski mediji & 30 oglasa ili 100\% & 0 oglasa ili 0\% & 7,3 \\
\hline $\begin{array}{c}\text { Nemački } \\
\text { mediji }\end{array}$ & $\begin{array}{c}563 \text { oglasa ili } \\
58,9 \%\end{array}$ & $\begin{array}{c}392 \text { oglasa ili } \\
41 \%\end{array}$ & 18,2 \\
\hline
\end{tabular}

Tabela 5. Lični oglasi objavljeni 2001. godine

\begin{tabular}{|c|c|c|c|}
\hline Medij & Kraći oglasi & Duži oglasi & $\begin{array}{c}\text { Prosečna dužina } \\
\text { oglasa prema } \\
\text { broju informa- } \\
\text { cionih jedinica }\end{array}$ \\
\hline Srpski mediji & 76 oglasa ili $86,3 \%$ & $\begin{array}{c}12 \text { oglasa ili } \\
13,6 \%\end{array}$ & $\begin{array}{c}\text { 7,8 samo u } \\
\text { štampanim } \\
\text { medijima; } \\
\text { 11,8 u svim } \\
\text { medijima } \\
\end{array}$ \\
\hline $\begin{array}{l}\text { Nemački } \\
\text { mediji }\end{array}$ & $\begin{array}{c}329 \text { oglasa ili } \\
39,4 \%\end{array}$ & $\begin{array}{c}504 \text { oglasa ili } \\
60,5 \%\end{array}$ & $\begin{array}{c}13,1 \text { samo u } \\
\text { štampanim } \\
\text { medijima; } \\
\text { 19,1 u svim } \\
\text { medijima }\end{array}$ \\
\hline
\end{tabular}

Tabela 6. Lični oglasi objavljeni 2015. godine

12 Dužina oglasa ovde nije određena brojem reči kao lingvističkom kategorijom, već brojem informacionih jedinica - količinom informacionih segmenata koje oglas sadrži, a koji imaju određeno sadržajno punjenje. Tako npr. oglas: „Dipl.-Ing. Mitte 50, 1,80, sucht Frau für eine treue und ehrliche Partnerschaft. Hobbys: Reisen, Joggen und Kultur. BMB und Telefon Angabe." (KSA 2015) sadrži 12 informacionih jedinica, a oglas: „Momak, 37 god, BG, prijatnog izgleda, traži devojku radi ozbiljne veze." (HO 2015) sadrži 7 informacionih jedinica. 
Lični oglasi objavljeni u srpskim medijima su isključivo kratki (2001. godine) ili uglavnom kratki (2015. godine). To svakako ima veze s finansijskim aspektom (svaka reč se pažljivo meri kad se ima u vidu cena oglasa). Međutim, s obzirom na to da producenti prilikom formiranja oglasa imaju u vidu publiku kojoj se obraćaju, anticipirajući reakcije i pokušavajući da izazovu maksimalno pozitivan efekat, ovakav podatak daje nam informacije i o čitaocima oglasa, njihovoj pažnji i očekivanjima. Objavljivanje oglasa u srpskom društvu nije samo stvar finansijske situacije, već ima veze i s mentalitetom naroda, koji upoznavanje potencijalnih partnera radije obavlja na drugačiji način, što se evidentno pokazuje i kroz apsolutan broj objavljenih oglasa.

U nemačkim medijima 2001. godine većina oglasa ulazi u kategoriju kraćih, ali su duži oglasi ipak prisutni, što potpuno odstupa od prakse u Srbiji. Kako bi se bolje razumela takva statistika, treba napomenuti da se nemačko društvo, kao moderno i razvijeno, nosi i s određenim problemima: (post)moderni razvoj dodatno potencira individualizam i orijentaciju na sebe, pa su druženja svedena na povremena ili retka, što je u Srbiji nezamislivo. U takvoj situaciji vremena za upoznavanje putem direktnih kontakata gotovo da nema, pa je, s jedne strane, razumljiv povećan broj oglasa koji nalazimo u medijima, a s druge i njihov obim. U vezi s tim je i veći broj informacionih jedinica u oglasima - kako za opis sebe, tako i za opis partnera ili potencijalne veze - jer se afirmativan i detaljan način opisivanja ne smatra neuobičajenim, preteranim ili hvalisavim kako bi to bilo shvaćeno u Srbiji. Osim kulturološkog aspekta, radi se i o krajnje praktičnim činjenicama, kao što su cena oglasa, kultura štampanih i elektronskih medija, tiraž novina, publika koja ih čita slično.

\subsection{Lični oglasi prema dominantnom sadržajnom usmerenju}

Donekle u vezi sa prethodnim kriterijumom jeste i dominantno sadržajno usmerenje oglasa. Radi se, naime, o klasifikovanju oglasa prema tome da li u njima dominira opis oglašivača, opis potencijalnog partnera ili opis poželjnog odnosa odnosno tipa veze. ${ }^{13}$ Ovakva

13 Prilikom utvrđivanja koji od ova tri dela oglasa prevladava, kao merodavni instrument korišćen je broj informacionih jedinica koje oglašivač navodi o sebi, o drugome ili o vezi. Ukoliko je broj informacionih jedinica ujednačen, kao značajniji, upečatljiviji, a time i dominantniji opis uzet je onaj koji je naveden na početku, jer je to mesto koje najpre izaziva pažnju. 
klasifikacija, iako zasnovana na merljivom kriterijumu, ipak daje samo okvirne naznake o dominantnom sadržaju oglasa jer se pretpostavlja da je mali broj oglasa isključivo posvećen opisu sebe ili samo opisu partnera pošto bi to odstupalo od uobičajene forme ove tekstualne vrste i od sadržaja koji se u njoj očekuje, pa bi samim tim realizacija komunikativne namere i efekat oglasa u velikoj meri bili dovedeni u pitanje.

\begin{tabular}{|c|c|c|c|}
\hline Medij & $\begin{array}{c}\text { Oglasi orijentisani } \\
\text { na opis oglašivača }\end{array}$ & $\begin{array}{c}\text { Oglasi orijentisani } \\
\text { na opis potencijal- } \\
\text { nog partnera }\end{array}$ & $\begin{array}{c}\text { Oglasi orijentisa- } \\
\text { ni na opis veze }\end{array}$ \\
\hline $\begin{array}{c}\text { Srpski } \\
\text { mediji }\end{array}$ & 19 oglasa ili 63,3\% & 10 oglasa ili 33,3\% & 1 oglas ili 3,3\% \\
\hline $\begin{array}{c}\text { Nemački } \\
\text { mediji }\end{array}$ & 542 oglasa ili $56,7 \%$ & 328 oglasa ili & 85 oglasa ili \\
\end{tabular}

Tabela 7. Lični oglasi objavljeni 2001. godine

\begin{tabular}{|c|c|c|c|}
\hline Medij & $\begin{array}{c}\text { Oglasi orijentisani } \\
\text { na opis oglašivača }\end{array}$ & $\begin{array}{c}\text { Oglasi orijentisani } \\
\text { na opis potencijal- } \\
\text { nog partnera }\end{array}$ & $\begin{array}{c}\text { Oglasi orijentisa- } \\
\text { ni na opis veze }\end{array}$ \\
\hline $\begin{array}{c}\text { Srpski } \\
\text { mediji }\end{array}$ & 48 oglasa ili $54,5 \%$ & 23 oglasa ili $26,1 \%$ & $\begin{array}{c}17 \text { oglasa ili } \\
19,3 \%\end{array}$ \\
\hline $\begin{array}{c}\text { Nemački } \\
\text { mediji }\end{array}$ & 401 oglas ili $48,1 \%$ & 246 oglasa ili $29,5 \%$ & $\begin{array}{c}186 \text { oglasa ili } \\
22,3 \%\end{array}$ \\
\hline
\end{tabular}

Tabela 8. Lični oglasi objavljeni 2015. godine

Oglasi u srpskim medijima pokazuju da se fokus najčešće stavlja na oglašivača, nešto ređe na potencijalnog partnera, dok se oglasi u kojima je primaran opis veze uglavnom pojavljuju u elektronskom formatu. Ovakav zaključak odnosi se na obe istražene godine. Isticanje sopstvenih karakteristika i osobina svodi se na najjednostavniji postupak dovođenja subjekta u centar pažnje, s ciljem usmeravanja pogleda ka njemu.

U ovoj kategoriji nemački lični oglasi, dajući primat opisu sebe, pokazuju slične ili gotovo iste tendencije kao i srpski. Na drugom 
mestu se nalazi opis željenog partnera, dok je opis veze i ovde u većoj meri zastupljen samo kod oglasa objavljenih na internetu.

\section{Zaključak}

Istraživanje ličnih oglasa u okviru kulture iz koje su proistekli, a polazeći od principa lingvistike teksta, omogućilo je sagledavanje ovog formata kao dela društvene stvarnosti s jedne strane i lingvističkog fenomena s druge. Ova dvostranost pristupa pozicionira lične oglase na idealno mesto za proučavanje s različitih polaznih osnova u zavisnosti o cilja analize. Oni nastaju kao stvaralački čin pojedinca, s ciljem uspostavljanja kontakta s potencijalnim partnerom, a njihovo delovanje i njihov značaj prevazilaze okvire individualnog jer pružaju uvid u kulturološki utemeljene obrasce delanja, ponašanja i razmišljanja. Različiti tipovi ličnih oglasa posredno, kroz kategorije u kojima se realizuju, odražavaju brojne vrednosti koje dominiraju u nekom društvu: odnos muškaraca i žena, stepen modernizacije, društveno prihvatljivog ponašanja i delanja i dr. Kontrastivno proučavanje srpskog i nemačkog korpusa pokazalo je da je srpsko društvo u procepu između tradicionalnih formi, hijerarhije i zadržavanja postojećih obrazaca s jedne strane i težnje ka modernizaciji i napretku s druge, dok se u nemačkom društvu ističu postmoderne vrednosti, tolerancija i novi modeli partnerstva, a pojedinci su okrenuti realizaciji sopstvenih želja i potreba.

\section{LITERATURA}

Bek 1986: Beck, U. (1986). Risikogesellschaft. Frankfurt a.M.: Suhrkamp. Brinker 1997: Brinker, K. (1997). Linguistische Textanalyse. Eine Einführung in Grundbegriffe und Methoden. 4. Aufl. Berlin: Erich Schmidt Verlag.

Brinker 2000: Brinker, K. (2000). Textfunktionale Analyse, u: K. Brinker, G. Antos, W. Heinemann, S. Sager (Hrsg.), Text- und Gesprächslinguistik. Ein internationales Handbuch zeitgenössischer Forschung. Berlin

- New York: Walter de Gruyter, 175-185. 
Dimter 1981: Dimter, M. (1981). Textklassenkonzepte heutiger Alltagssprache. Kommunikationssituation, Textfunktion und Textinhalt als Kategorien alltagssprachlicher Textklassifikation. Reihe Germanistische Linguistik, Band 32. Tübingen: Niemeyer.

Dofifat i Vilke 1976: Dovifat, E, Wilke, J. (1976). Zeitungslehre. Berlin New York: Walter De Gruyter.

Ganzel 2011: Gansel, C. (2011). Textsortenlinguistik. Göttingen: Vandenhoeck \& Ruprecht GmbH.

Hajneman 2000: Heinemann, M. (2000). Textsorten des Alltags, u: K. Brinker, G. Antos, W. Heinemann, S. Sager (Hrsg.), Text- und Gesprächslinguistik. Ein internationales Handbuch zeitgenössischer Forschung. Berlin - New York: Walter de Gruyter, 604-614.

Hofart 2009: Hoffarth, F. (2009). Queer dating. Eine kontrastive Untersuchung von Kontaktanzeigen in Online-Magazinen für Schwule und Lesben. Duisburg: Universitätsverlag Rhein-Ruhr.

Kremer 1998: Kraemer, M. (1998). Partnersuche und Partnerschaft im deutsch-französischen Vergleich 1913-1993. Eine empirische Analyse zum Wertewandel anhand von Heirats- und Bekanntschaftsanzeigen. Münster/New York/München/Berlin: Waxmann Verlag.

Marfurt 1978: Marfurt, B. (1978). Textsorten und Interaktionsmuster, Wirkendes Wort 28. Düsseldorf: Schwann, 19-36.

Riman 1999: Riemann, V. (1999). Kontaktanzeigen im Wandel der Zeit. Eine Inhaltsanalyse. Opladen/Wiesbaden: Westdeutscher Verlag.

Rolf 2000: Rolf, E. (2000). Textuelle Grundfunktionen, u: K. Brinker, G. Antos, W. Heinemann, S. Sager (Hrsg.), Text- und Gesprächslinguistik. Ein internationales Handbuch zeitgenössischer Forschung. Berlin New York: Walter de Gruyter, 422-435.

Rutkovski 2003: Rutkowski, N. (2003). Kontaktanzeigen im intermedialen Vergleich. Essen: Redaktion LINSE.

Štolt 1976: Stolt, B. (1976). „Hier bin ich - wo bist Du?“ Heiratsanzeigen und ihr Echo analysiert aus sprachlicher und stilistischer Sicht. Mit einer soziologischen Untersuchung von Jan Trost. Kronberg/Ts: Scriptor Verlag.

Zomerfelt 2001: Sommerfeldt, K. E. (2001). Zu Inhalt und Sprache von Familienanzeigen, u: K. E. Sommerfeldt, H. Schreiber (Hrsg.), Textsorten des Alltags und ihre typischen sprachlichen Mittel. Frankfurt/M: Peter Lang, 24-34. 


\title{
Nina Polovina
}

Tanja Dinić

\section{TYPOLOGY OF PERSONAL DATING ADVERTISEMENTS AS LINGUISTIC AND CULTURAL CATEGORIES}

\begin{abstract}
Summary
The study of personal dating ads within their cultural context, based on the text linguistics principle, enabled insight into this format as an element of the social reality on the one side, and a linguistic phenomenon on the other. Such double approach places the ads at an ideal position for study from various starting points, depending on the analysis objective. They are the result of a creative process of an individual and they aim at contacting a potential partner, but their specific function and importance go beyond their individual character since they allow for understanding culture-based models of doing, behaviour and reflexion. Considering two mass communication media - press and the Internet, the dating ads are defined in terms of function and pattern, as well as their context. An ads typology is then proposed in order to provide a grounding for culturological interpretation since various types of personal dating advertisements indirectly reflect dominant values of a given society through categories they are produced in: men-women relationships, degrees of modernization, socially acceptable behaviour and doing etc. A contrastive analysis of Serbian and German corpora showed that the two cultures are based on some identical general human values, but pointed out a gap Serbian society finds itself in, between traditional forms, hierarchy and conservative forms on the one hand, and a tendency towards modernization and progress on the other. German society, though, favours postmodern values, tolerance and recent partner models and individuals generally search fulfillment of their own desires and needs.
\end{abstract}

Key words: communication, culture, language, medium, personal dating advertisement, society, text type, typology, value

Примљено 5. септембра 2016. године Прихваћено за објављивање 15. новембра 2016. године 